\title{
Serum amyloid-A protein concentration in rheumatoid arthritis and its role in monitoring disease activity
}

\author{
R. E. CHAMBERS, ${ }^{1}$ D. G. MACFARLANE, ${ }^{2}$ J. T. WHICHER, \\ AND P. A. DIEPPE ${ }^{2}$ \\ From the Department of ${ }^{1}$ Chemical Pathology and ${ }^{2}$ Medicine, Bristol Royal Infirmary and University of Bristol, \\ Bristol
}

SUMMARY The serum concentrations of serum amyloid-A protein (SAA), C-reactive protein (CRP), and alpha ${ }_{1}$-acid glycoprotein $\left(\right.$ alpha $\left._{1}-A G P\right)$ have been measured in 185 patients with rheumatoid arthritis. SAA and CRP concentrations correlated well $(r=0 \cdot 86)$ both within and above the normal ranges, though SAA showed a greater incremental increase than CRP. All patients with normal SAA levels also had normal CRP and alpha $a_{1}$ AGP concentrations. In

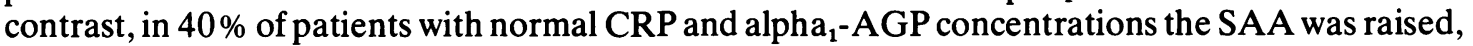
sometimes markedly so. The clinical and serological assessments of disease activity in these patients were not significantly different from those with concomitantly raised levels of CRP. These findings suggest that SAA is a more sensitive marker of inflammation than is CRP. The role of the measurement of SAA as a monitor for inflammatory disease activity is discussed.

Measurements of the serum acute-phase proteins are of value in the assessment of the activity and prognosis and also in the monitoring of response to treatment in chronic inflammatory diseases such as rheumatoid arthritis. ${ }^{1-3} \mathrm{C}$-reactive protein (CRP) has been most widely used in this context. ${ }^{4}$ More recently a new acute-phase protein, serum amyloid-A (SAA) protein, has been described. ${ }^{56}$ SAA is a normal alpha ${ }_{1}$ globulin which is thought to be the circulating precursor of tissue amyloid-AA. Increased concentrations of SAA have been reported in a number of inflammatory diseases, ${ }^{78}$ including rheumatoid arthritis (RA) and juvenile rheumatoid arthritis. $^{910}$

Despite the fact that the evidence suggests a single macrophage-derived messenger (interleukin I) as being responsible for switching on acute-phase protein synthesis in the liver, ${ }^{11}$ not all acute-phase proteins are raised in parallel in many diseases. ${ }^{12}$ These discrepancies may result from differential consumption of proteins in the inflammatory process or a selective response on the part of the liver. Whatever the explanation, the phenomenon suggests that certain of the acute-phase proteins may be of particular

Accepted for publication 11 January 1983.

Correspondence to Dr R. E. Chambers, Department of Chemical Pathology, Bristol Royal Infirmary, Bristol BS2 8HW. use for monitoring activity in different diseases. We have set out to determine whether the measurement of SAA provides further useful clinical information in rheumatoid arthritis beyond that provided by the widely used measurement of CRP. We have thus compared SAA, CRP, and another acute-phase protein, alpha $a_{1}$-acid glycoprotein $\left(\text { alpha }_{1}-A G P\right)^{13}$ in the light of conventional clinical and serological assessments in this disease.

\section{Patients and methods}

Inpatients and outpatients were included in the study. Data on age, sex, duration of rheumatoid arthritis, presence of systemic features, and drug therapy were recorded. Disease activity was assessed clinically and by haemoglobin and plasma viscosity measurement. $X$-rays were examined for the presence of erosions, and theumatoid factor was estimated. The patients could thus be broadly categorised as having early active, active erosive, and inactive or long-standing destructive disease.

Serum was separated from clotted venous blood and stored at $-20^{\circ} \mathrm{C}$. SAA levels were measured by a modified radial immunodiffusion method described elsewhere. ${ }^{14}$ CRP was measured by simple radial immunodiffusion ${ }^{15}$ and alpha $_{1}$-AGP by the Laurell 
rocket technique. ${ }^{16}$ The normal ranges were established by means of samples from 200 normal, healthy blood donors and expressed as 5 th to 95 th percentiles are: SAA less than 5-30 $\mathrm{mg} / \mathrm{l}$; CRP less than 5-11 $\mathrm{mg} / \mathrm{l}$, and alpha $\mathrm{A}_{1}$-AGP $0 \cdot 55-1.40 \mathrm{~g} / \mathrm{l}$.

\section{Results}

A total of 185 patients with rheumatoid arthritis were studied over a period of one year. In some cases acute-phase proteins were measured on more than one occasion, resulting in 305 sets of measurements.

A comparison of serum SAA and CRP concentrations is shown in Fig. 1. There is a correlation of the results $(r=0 \cdot 86)$ over a wide range of concentrations, both within and above the normảl ranges. SAA, however, shows a greater incremental change in rheumatoid arthritis than CRP, the maximum observed concentration being in the range of 3 to $4 \mathrm{~g} / \mathrm{l}$

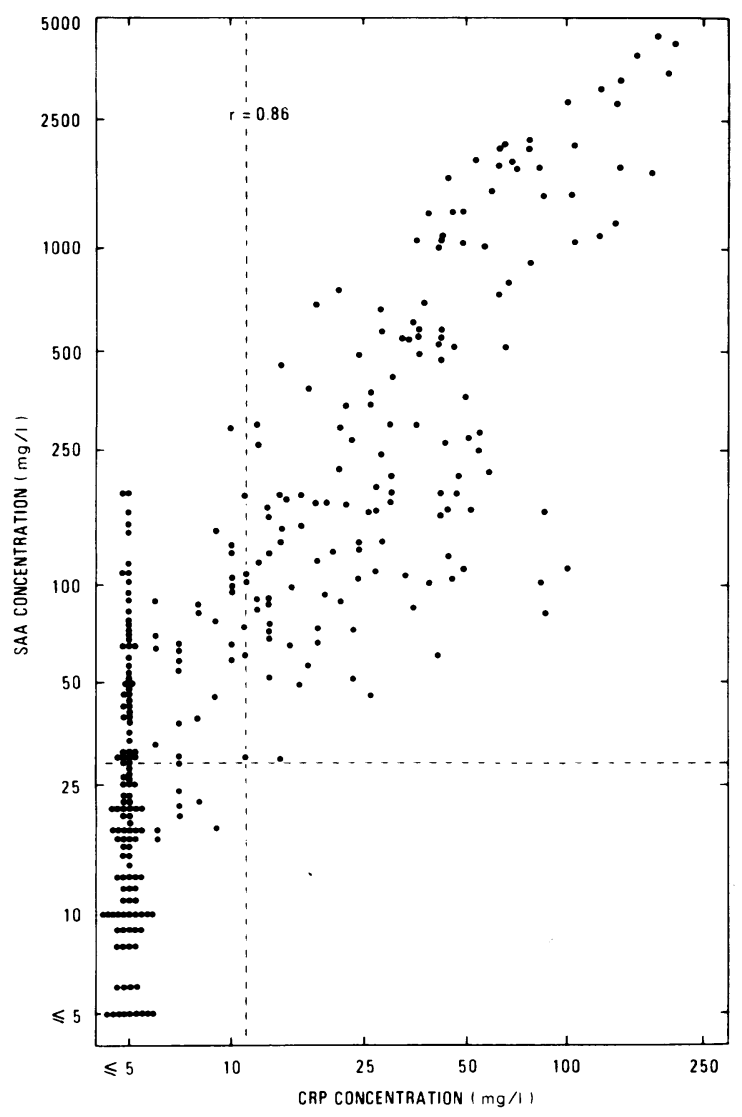

Fig. 1 Correlation of $S A A$ and CRP concentrations in rheumatoid arthritis. The dotted lines delineate the upper limit of the normal range.

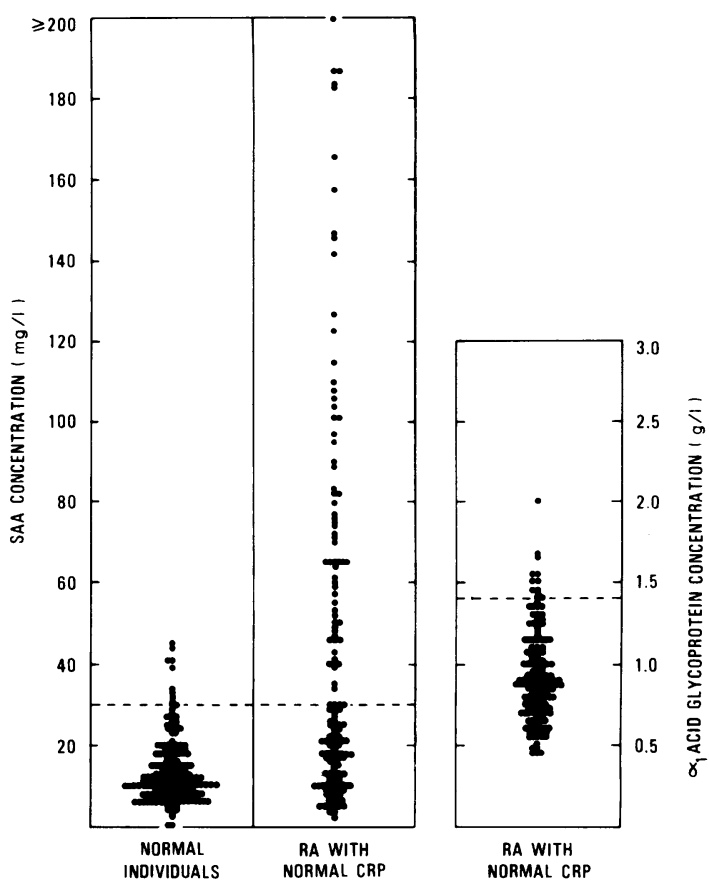

Fig. 2 Comparison of $S A A$ concentrations in normal individuals and $R A$ patients all of whom had normal $C R P$ concentrations. Alpha $a_{1}$-AGP concentrations in the RA group are also shown. The dotted lines delineate the upper limit of the normal range.

as compared with CRP levels of 200 to $250 \mathrm{mg} / \mathrm{l}$. More interestingly it can be seen that increased SAA levels are present in the face of normal CRP concentrations. This is clearly illustrated in Fig. 2, where the SAA levels for all patients who had normal CRP concentrations have been plotted alongside the SAA levels in healthy blood donors also with normal levels of CRP. SAA is raised in $40 \%$ of instances in which the CRP concentration is normal, sometimes markedly so, with the maximum observed level being 8 times the upper limit of normal. In contrast, alpha ${ }_{1}-$ AGP levels showed no significant increase in the same group of samples, $94 \%$ of the values lying within the normal range.

The samples showing raised SAA and normal CRP were not more frequent among replicates from certain patients, nor was there any significant difference in sex, disease activity and duration, seropositivity, plasma viscosity, administration of second-line therapy, or presence of erosive damage on $x$-ray between this group and those with concomitantly raised CRP levels. However, in 80 samples with normal SAA levels there were no cases with raised concentrations of CRP. 


\section{Discussion}

These findings are of considerable interest, as they illustrate the discrepancies which may be found between different acute-phase proteins in a chronic inflammatory disease such as rheumatoid arthritis. Moreover they demonstrate that SAA has considerably greater sensitivity than CRP in detecting the presence of inflammation.

Dissociation between the responses of a number of acute-phase proteins is well known. In the case of haptoglobin, fibrinogen, and complement components it is easily explained on the basis of specific consumption by certain elements of the inflammatory process. Thus intravascular haemolysis consumes haptoglobin, ${ }^{17}$ fibrinogen is rapidly eliminated from the circulation if intravascular coagulation occurs, ${ }^{17}$ and deposition of immune complexes activates and consumes complement components such as $\mathrm{C} 3 .^{18}$ Besides this mechanism it appears that serum levels of some acute-phase proteins increase much more rapidly and sensitively than others. ${ }^{19}$ Mild inflammation may thus cause increases in CRP while not affecting such proteins as fibrinogen, alpha ${ }_{1}-\mathrm{AGP}$, and haptoglobin. The data presented here suggest that SAA is even more sensitive than CRP in response to the inflammatory lesion of rheumatoid arthritis. There is no evidence to suggest that either of these proteins is actively consumed by the inflammatory process, and it seems likely that SAA synthesis in the hepatocyte is more easily switched on by interleukin I than is that of CRP or alpha ${ }_{1}$-AGP.

The discrepancies between the responses of different acute-phase proteins seen in inflammatory diseases, particularly of a chronic nature, have led many workers to monitor disease activity by measuring a number of acute-phase proteins simultaneously. ${ }^{20}$ While this is more expensive it is probably more effective than relying on one alone. It seems that SAA is a more sensitive acute-phase reactant in rheumatoid arthritis than CRP and may well allow monitoring of disease activity in those patients in whom the most sensitive acute-phase protein hitherto measured, CRP, is normal. SAA is relatively easy to measure and could usefully be either measured alone or added to CRP assays in monitoring chronic inflammatory diseases, such as rheumatoid arthritis. Indeed in our present series of 80 instances in which normal levels of SAA were found none had a raised CRP. It will of course be of considerable interest to see if these findings hold in other inflammatory conditions.

\section{References}

1 McConkey B, Crockson R A, Crockson A P. The assessment of rheumatoid arthritis. A study based on measurements of the serum acute-phase reactants. $Q J$ Med 1972; 41: 115-25.

2 McConkey B, Crockson R A, Crockson A P, Wilkinson A R. The effects of some anti-inflammatory drugs on the acute-phase proteins in rheumatoid arthritis. $Q J$ Med 1973; 42: 785-91.

3 McConkey B, Davies P, Crockson R A, et al. Effects of gold, dapsone, and prednisone on serum $C$-reactive protein and haptoglobin and the erythrocyte sedimentation rate in rheumatoid arthritis. Ann Rheum Dis 1979; 38: 141-4.

4 Pepys M B. C-reactive protein fifty years on. Lancet 1981; i: 653-7.

5 Gorevic P D, Rosenthal C J, Franklin E C. Amyloid-related serum component (SAA)-studies in acute infections, medullary thyroid carcinoma and postsurgery. Behaviour as an acutephase reactant. Clin Immunol Immunopathol 1976; 6: 83-93.

6 McAdam K P W J, Elin R J, Sipe J D, Wolff S M. Changes in human serum amyloid $A$ and $C$-reactive protein after etiocholanolone-induced inflammation. J Clin Invest 1978; 61: 390-4.

7 Rosenthal C J, Franklin E C. Variation with age and disease of an amyloid $\mathbf{A}$ protein-related serum component. J Clin Invest 1975; 55: 746-53.

8 De Beer F C, Mallya $R$ K, Fagan E A, Lanham J G, Hughes G R V, Pepys M B. Serum amyloid-A protein concentration in inflammatory diseases and its relationship to the incidence of reactive systemic amyloidosis. Lancet 1982; ii: 231-4.

9 Benson M D, Cohen A S. Serum amyloid-A protein in amyloidosis, rheumatic and neoplastic diseases. Arthritis Rheum 1979; 22: 36-42.

10 Scheinberg M O, Hubscher O, Morteo O G, Benson M D. Serum amyloid protein levels in South American children with rheumatoid arthritis: a co-operative study. Ann Rheum Dis 1980; 39: 228-30.

11 Sipe J D, Vogel S N, Sztein M B, Skinner M, Cohen A S. The role of interleukin $I$ in acute phase serum amyloid $A$ (SAA) and serum amyloid P (SAP) biosynthesis. Ann NY Acad Sci 1982; 389: 137-50.

12 Pepys M B. Serum C-reactive protein, serum amyloid P-component and serum amyloid $\mathbf{A}$ protein in autoimmune disease. Clin Immunol Allergy 1981; 1: 77-101.

13 Schmid K. Alpha $a_{1}$-acid glycoprotein. In: Putnam F W, ed. The plasma proteins. New York and London: Academic Press, 1975: 1: $183-228$.

14 Chambers R E, Whicher J T. Quantitative radial immunodiffusion assay for SAA. J Immunol Methods in press.

15 Mancini G, Carbonara A O, Heremans J F. Immunochemical quantitation of antigens by single radial immunodiffusion. Immunochemistry 1965; 2: 235-54.

16 Laurell C-B. Quantitative estimation of proteins by electrophoresis in agarose gel containing antibodies. Anal Biochem 1966; 15: 45-52.

17 Laurell C-B. The use of electroimmunoassay for determining specific proteins as a supplement to agarose gel electrophoresis. J Clin Pathol 1975; 28 (suppl 6): 22-6.

18 Whicher $\mathrm{J} T$. The value of complement assays in clinical chemistry. Clin Chem 1978; 24: 7-22.

19 Fischer C L, Gill C, Forrester M G, Nakamura R. Quantitation of acute phase proteins postoperatively. Am J Clin Pathol 1976; 66: 840-6.

20 Laurent M R, Panayi G S, Shepherd P. Circulating immune complexes, serum immunoglobulins, and acute phase proteins in psoriasis and psoriatic arthritis. Ann Rheum Dis 1981; 40: 66-9. 